\title{
A JOURNEY OF LEARNNG: RELATIONS WITH THE LAND, ENVIRONMENTAL VIOLENCE AND DISPOSSESSION, AND DECOLONIZING SOCIAL WORK
}

\author{
by
}

Lauren Anderson, BSW, Western University, 2019

\author{
An MRP \\ presented to Ryerson University \\ in partial fulfillment of the \\ requirements for the degree of \\ Master of Social Work \\ in the program of \\ Social Work
}

Toronto, Ontario, Canada, 2020

(C) Lauren Taylor Anderson, 2020 


\begin{abstract}
AUTHOR'S DECLARATION
I hereby declare that I am the sole author of this MRP. This is a true copy of the MRP, including any required final revisions.
\end{abstract}

I authorize Ryerson University to lend this MRP to other institutions or individuals for the purpose of scholarly research

I further authorize Ryerson University to reproduce this MRP by photocopying or by other means, in total or in part, at the request of other institutions or individuals for the purpose of scholarly research.

I understand that my MRP may be made electronically available to the public. 


\begin{abstract}
A Journey of Learning: Relations with the Land, Environmental Violence and Dispossession, and Decolonizing Social Work

Master of Social Work, 2020

Lauren Anderson

Social Work,

Ryerson University
\end{abstract}

For the purposes of this Major Research Paper (MRP), I have chosen to situate my project in a position of intentional engagement with attempts to challenge settler colonialism. Toward this goal, I attempt to engage in learning about ways in which social work can engage in intentions of decolonizing. As a woman of mixed ancestry - both of settler and Haudenosaunee background - this MRP uses the Petal Flower Framework (Absolon, 2011) to support the process of learning of relations with Creation (the natural environment), with consideration of social work practice, and the ongoing systems which perpetuate violence against the environment. The journey involved in this process has included intentional thought in attempt to learn from Indigenous authors as I strive to decolonize my personal and professional journeys. 


\section{ACKNOWLEDGEMENTS}

To those who have walked beside me and held me up along this journey-thank you. The completion of this paper is supported by the care of many around me. Special thanks to both of my parents for their ongoing support with my endeavors in learning and growth. I am eager to continue my time in the field. I anticipate that while this marks the end of a journey in school, I will continue with life-long learning.

I would like to thank my research supervisor, Dr. Gordon Pon for his ongoing support with my learning in this program as I navigated this research journey. 


\section{TABLE OF CONTENTS}

$\begin{array}{ll}\text { Introduction } & 1\end{array}$

$\begin{array}{ll}\text { Theoretical Framework } & 5\end{array}$

$\begin{array}{ll}\text { Topical Learning -A Review of Writing } & \mathbf{7}\end{array}$

Indigenous Relations with The Environment: An Exploration through Learning and Literature

Indigenous Knowledges Related to the Natural Environment \& Considering Treatment of Indigenous Knowledges 13

Environmental Violence/Racism \& Dispossession on Turtle Island: 17

Environmental Social work: What is it and Where is it in Practice? 19

Methodology: 24

"The Roots" (Absolon, 2011, pp. 53-66 ):

"The Centre of the Flower" (Absolon, 2011, pp. 67-84): 27

"The Leaves: The Methodological Journey: (Absolon, 2011, pp. 85-95): 28

"The Stem: Backbone and Supports" (Absolon, 2011, pp. 96-117): 29

"The Petals: Diverse Methodologies" (Absolon, 2011, pp. 118-139): 29

Data Collection:

Learning from Writing and a Conversation of Learning: 35

"Land Back: A Yellowhead Institute Red Paper" (King \& Pasternak, 2019): 35

Connected Systems \& Structures:

Consent and Self-Determination 37

Indigenous Knowledges, Decision-Making \& Considerations of the Climate Crisis: $\quad 40$

Considering Colonial Dynamics of Gender:

Resistance: $\quad 44$

Asking Questions \& Going Further:

Implications: For me, and For Decolonizing Social Work: 49

Conclusion and Continuing Learning: $\quad 54$

$\begin{array}{ll}\text { References } & 56\end{array}$ 


\section{Introduction}

This research project began as a learning opportunity as per the requirements of Ryerson's MSW program. This project has since become something of much more meaning to me. Throughout this journey, I have had the opportunity to create a process which encouraged learning, unlearning, intention, and reflection.

For the purposes of this Major Research Paper, I will be focusing on Indigenous Knowledges and relationship with the environment, with consideration of how Indigenous communities act in resistance despite ongoing colonial acts of violence towards the land (i.e., violence that is operationalized through actions of environmental racism $^{1}$ ). As a woman of mixed Haudenosaunee and European-settler background, I find myself interested in exploring this topic as I further develop and learn of my relations with Creation. Further, I have positioned this journey as an opportunity to dedicate and take time to learn as someone within this field of work. This paper is not intended to unveil pre-existing ideas and worldviews within Indigenous communities, rather this journey has allowed myself an opportunity to dedicate time in learning from Indigenous folks as I intentionally attempt to engage with ongoing decolonization, while also attending to my relation with Creation. While embarking on this journey, it felt pertinent to also take space in learning how Indigenous folks' experiences are being impacted by ongoing environmental violence and racism, and access to land and waters.

This paper is situated as an intentional attempt to decolonize the Major Research Paper process and outcome. This paper has been curated with ongoing consideration of ways I hope to

${ }^{1}$ Environmental racism is understood as the heightened or disproportionate amount of environmental violence which takes place in communities of minority peoples and/or which are marginalized. Environmental racism often involves an increase of contamination or pollution of natural resources (Dhillon \& Young, 2010, as cited in McGregor, 2016, p. 38). 
act with respect, reciprocity, and resistance within the structure of Western academia. I attempt to carry and hold myself accountable to the unique ways in which I see my responsibilities, and roles as someone who accesses privileges because I am white-coded within [a settler colonialist, white supremacist, patriarchal and capitalist] society. Ineese-Nash (2019) speaks to some of the unique roles' Indigenous folks of mixed ancestry may have in the following quote: "We must be careful to respect traditional knowledge as something to be shared but not commodified or appropriated. And we must also seek ways to make colonial structures less harmful to Indigenous people to come" (p. 6). I do not identify as someone whose personal lived experiences have been impacted by environmental violence, but I see this topic as one which relates to my responsibility to learn.

This paper attempts to prioritize respect for Indigenous Knowledges as I continue on my path of learning and connecting with Creation, while also attempting to resist the structures which perpetuate violence against Indigenous folks and Creation through methods of environmental violence, dispossession, and jurisdiction. Furthermore, for myself, it is significant to recognize and name the privileges that I access when discussing my identity, and the ways which I navigate space as a woman of white-settler and Haudenosaunee ancestry. With this said, I seek to learn and unlearn. My whiteness is too a part of my identity that has allowed me significant privileges; recognizing these privileges has encouraged me to hold myself accountable and responsible to learning and unlearning.

I believe it is important that I reflect on where I have gained knowledges and my understandings of the world as I hope to recognize and credit those who have helped me come to where I am today. I have learned of a way which this may support my hopes of being accountable to those who have come before us and those who have shared their knowledges with 
others (Marsden, 2005, as cited in Absolon, 2010, p. 75). I was raised in a household surrounded by many women, and my father. I was taught my education from home by my mom, and others until I was 12 years old. Learning from home allowed me great opportunity to learn through experiences. I was able to go to our family farm or be a helper to my dad as we went on adventures which almost always included time spent with animals.. While writing a significant amount of this paper, I have had the opportunity to be welcomed back to the same backyard where I did my first years of learning. It feels meaningful to be coming home as I finish my formal education career in the place where it first began. I believe my learning will extend far beyond my farewell to institutional education.

Later on, I was taught in public education and was privileged to start my postsecondary journey after completing high school. In postsecondary studies, I was taught names of theories behind various knowledges; some of which I had already believed in, such as feminism. I was also introduced to several new ideas and concepts, such as decolonization. I was not raised with traditional knowledges of Haudenosaunee people, but have actively attempted to reconnect with these knowledges and teachings in ways that feel appropriate with where I am at in my journey. I believe my journey in connecting with Haudenosaunee culture will be lifelong. Some of the ways I have learned is from reading version of Haudenosaunee Creation Story, and the Thanksgiving Address shared by McGregor (2004). My engagement with this topic is in an effort to further learn from Indigenous people, and to expand my learning as a Haudenosaunee woman in the field of social work. Absolon (2010) speaks about reconnection of culture within practice and helping roles in the following quote:

Our work as wholistic practitioners is to remember and 
reconnect with wholistic knowledges, pick up our bundles and activate them again. Picking up our bundles means to relearn, reclaim, pick up and own the teachings and practices that emanate from wholistic theory and knowledge. (Absolon, 2010, p. 75)

This quote reflects my interest in this topic as a person who is attempting to make intentional choices to engage and learn of Indigenous Knowledges as it relates to my relationship with Creation, and to my practice in the profession of social work. This project is one attempt to expand my bundle.

The topic of Indigenous Knowledges and relationship to the land relates to social work for a multitude of reasons. I see this topic relevant to social work practice because it is pertinent for helpers and professionals in this field to learn about land-based relations and environmental violence, and thus how these concepts may connect with our practice and more broadly, such as how we relate with the spaces that we occupy. I recognize this curiosity as the place of wondering which prompted my interest in this topic at the beginning of this project. As someone who is particularly passionate about the need for decolonizing and accountability to Indigenous folks by the field of social work - I wanted to better understand the ways which land-based relations may be involved in this through learning and critical thought. Further, this learning and responsibility feels important for folks who occupy space on Turtle Island ${ }^{2}$. Indeed, it is important for social workers to increase their consciousness around settler-hood and what this might mean for relationship with the land that they are situated on and engage with. Furthermore,

${ }^{2}$ Turtle Island is often referred to as the lands which make up North America. Baskin is one author who identifies this as a commonly used understanding (2016, p. 4). 
it is critical to recognize that social work as a profession has and continues to contribute to colonization in Canada in a multitude of ways (Baskin, 2016, p.11-13; Hiller \& Carlson, 2018, p. 52). The complicity of the field of social work in colonization has been noted by Hart (2002 as cited in Baskin, 2016, p. 12). I recall when I originally learned of the specific ways which this profession has been so connected to the systems of colonialism. Since then, there have been times when I have had conflicting emotions as I reflect on 'my role' within this system. This paper is influenced and motivated by the need for decolonizing social work. My exploration of this topic (as an intentional way to dedicate time and space for learning) is, I contend, one way to advocate for decolonization of the profession of social work.

\section{Theoretical Framework}

For the purposes of this MRP and the perspective I am coming from as a writer, this paper is informed by anti-colonial, de-colonizing, and Indigenous theoretical frameworks. For this reason, I have chosen to turn to the writings of several Indigenous scholars (some nonIndigenous authors as well) who speak of research within an Indigenous context. Anticolonialism involves the political and actionable stance which resists colonialism and the practices involved with colonization (Hart, 2009a). Hart further explains anti-colonialism in the following statement: "[it] questions institutional power and privilege and the rationale for dominance, and acknowledges the intertwining role state, societal and institutional structures play in producing and reproducing inequalities" (2009a, p. 30). Moreover, the connection of anticolonial theory and implementation of an Indigenous Research Paradigm within the context of this research seems appropriate. In my learning about Indigenous Research, Shawn Wilson (2008), Michael Hart (2009b), and Kathleen Absolon (2011) discuss the influence of the situation of Indigenous research as it seeks to be informed by Indigenous knowledges, practices, 
principles/values throughout the research process. In Hart's (2009b) discussion of "Indigenism" connectedness to the land - he states the following sentence: "It recognizes and supports kinship roles between the earth, people and other life and emphasizes that humankind cannot dominate nature" (Hart, 2009b, p. 35). While an Indigenist framework has uniqueness from an anticolonial approach or framework (as discussed by Hart, 2009b), this value of non-domination in relation to the natural environment will be returned to as a principle of value I have attempted to carry within and throughout this research process. Further, an Indigenist framework is informed by Indigenous worldview, which encompasses the importance of spirituality (Hart, 2009b, p. 35).

In the context of Turtle Island, research (knowledge production within Euro-centric perspectives) with and on Indigenous folks has a contentious relationship with an incredibly harmful past (Baskin, 2016, p. 322; Hart, 2009b, p. 27). It is important to consider the historical and contemporary concerns which exist surrounding research and Indigenous folks (Absolon, 2011, p. 27; Baskin, 2016, p. 322,). This reality is pertinent to consider as a person of nonIndigenous and Indigenous background who is engaging with a journey of research. I have attempted to situate this research paper within a recognition of this reality and made intentional choices throughout this journey with a significant amount of time reflecting on the importance of respect and appropriateness. With this knowledge, I see this research being led and influenced by my situation as a woman of mixed Indigenous and non-Indigenous background. I have been on a journey of actively, and intentionally attempting to engage with decolonizing.

My theoretical framework is informed by the writing of Tuck and Yang (2012). Tuck and Yang (2012) speak of concerns which arise when decolonizing language is used within academia without authentic intent to engage with the work required by decolonization. Implementing a decolonizing approach requires me to make a commitment to the "unsettling" nature of 
decolonization as an ongoing action with intention behind it (Tuck, \& Yang, 2012, p. 3). Further, my understanding of the current state is that which recognizes our existence in an ongoing condition of settler-colonialism (Tuck, \& Yang, 2012). For Tuck and Yang (2012), settler colonialism relies on the land and natural resources not only as a place to live, but also as a means of capital and threat to Indigenous culture. Consider the following as it relates to settler colonialism and the land:

This is both because the settlers make Indigenous land their new home and source of capital, and also because the disruption of Indigenous relationships to land represents a profound epistemic, ontological, cosmological violence. This violence is not temporally contained in the arrival of the settler but is reasserted each day of occupation. (Tuck \& Yang, 2012, p. 5)

This quote considers the complexity of settler colonialism and the violent ways in which it has taken place, alongside the multitude of impacts which are experienced by Indigenous folks. To me, it is critical to identify this consciousness of the settler-colonial state within the positioning of this paper.

\section{Topical Learning -A Review of Writing}

For the purposes of this literature review, I have created sub-categories of areas which I saw as connected or related topics. It felt important to cover the following subtopics in considering the strength and discourse of Indigenous land relations and resistance:

- Indigenous relations with the environment: An exploration through learning and literature 
- Indigenous Knowledges related to the natural environment \& Considering Treatment of Indigenous Knowledges

- Environmental violence and dispossession on Turtle Island

- Environmental social work: What is it and where is it in practice?

This literature review includes voices of Indigenous and non-Indigenous scholars and sharers. I have included empirical and non-empirical writings in attempt to support Indigenous experiences and knowledges and to resist the ways these knowledges may be negated, used or misinterpreted within research. All the references included in this review of literature are retrieved through online searches, library access, or via published hard-copy books. Further, I note that within this literature review there are contributions from authors with various educational/field experience beyond social work. I have included some of my thoughts related to the literature being presented (within my personal interpretation)- further understanding its relevance to the topic and purpose of this paper as I see appropriate and relevant. The development of these 'sections' aided and supported my learning, but it is important to note that this review of literature is not comprehensively representative of the literature which exists within these subtopics, rather I understood these to be foundational concepts for my learning about this topic. I have reflected on a gap in this search which I will identify as a limitation of this project. While I have been learning about issues related to land jurisdiction, relations with the land, dispossession, and environmental violence - I recognize a gap in this review of literature with respect to discussing the ways in which land tenure has/does take place and how lands are deemed by communities and/or the Crown. With this, the selection of reviewed material within the textual analysis will support some of the beginnings of my learning. I consider these understandings as pertinent learning related to the areas and territories we are 
situated on, but this topic is not specifically explored thoroughly within this research project. Again, I recognize that this project will not comprehensively discuss these issues as we consider the vast ways which land and settler colonialism are implicated within each other.

\section{Indigenous Relations with The Environment: An Exploration through Learning and Literature}

Along this journey, it was important for me to learn more about Indigenous relations with the natural environment. This was significant to me as I wanted to learn about how this may relate to my own experiences. I would like to begin this section with recognition of my goals to avoid generalization, or appropriation Indigenous Knowledges, and worldview. Further, I do not attempt to assert what individual identities of Indigenous folks might be, and what this means for their relations with the land - rather my reading of what some Indigenous folks say with regards to land-based relations was important to my learning. I do not expect or hold the belief that my presenting of writing which (as presented) speaks to relations with the land will be representative of all experiences or beliefs held by others. In my reflection and intentional choices made throughout this journey - it felt ignorant to exclude the ways which relations with the land may relate to worldview for folks. My learning about this topic will extend beyond reading or writing in this paper as I see my journey as a lifelong learning of reconnecting with culture.

I have put a lot of thought and consideration into the appropriateness of speaking about Indigenous culture and worldview pertaining to relations with the land. I have gathered writing from only a few authors who speak about this topic and attempted to represent their writing in ways which align with what they had written as per my interpretation. This section, and moreover this paper, is not a comprehensive review or understanding of these topics. It is also critical to consider as a limitation, the ways in which a 'review of literature' on this topic may be 
somewhat reductive and not representative of all folks' experiences or worldviews. I am cognizant that within this 'review of literature' the unique practices and understandings of individual nations and communities is not representative. I reflect on the writings of Wilson (2011, pp. 43-44), who discusses the application of others' work and projects (within the context of Indigenous research and application of a literature review). He identifies the following: “...by doing the review in a style that is not critical but builds upon the work of others, it can also form the context for relational accountability in working from an Indigenous paradigm" (Wilson, 2008, p. 44). This has influenced my positioning as I review other's writings, and I believe is relevant as well to my methodology, which is discussed in greater detail in the methodology chapter below.

In my learning, I have better appreciated the ways in which the environment and Creation carries great significance for many Indigenous communities and individuals across Turtle Island (McGregor, 2016, p. 22-23; LaDuke 1999 as cited in Richmond, 2018, p. 167). In learning from the writing of others (Hiller \& Carlson, 2018, p.50) - I agree and with the relevance of having appreciation for the ways which relations with the natural environment are particularly relevant and critical when considering the environmental violence which is happening on Indigenous lands. Further, Hiller and Carlson (2018) present the following relevant quote:

It is essential to hold in mind the integral importance of Indigenous relationships to their lands when seeking to understand the precise violence of settler colonialism, a structure and set of practices organized around an enduring imperative to elide, dismiss, deny, and extinguish these very relationships (Wolfe, 
2006). (Hiller \& Carlson, 2018, p. 50).

It has been critical for me to consider the ways in which relations with the environment are of great significance for many Indigenous communities (by McGregor, 2016, p.22). Another limitation to my study is that there exists much more knowledge and experiences beyond what I have recognized in literature review.

It feels important to begin with consideration for experiences with the natural environment, as I better understand environmental relationships. It is important to consider what is the meaning of "environment" within this paper? To me, this question also connects to the theoretical framework which is considered and applied to this paper. McGregor (2016) speaks to this question while identifying that within an Indigenous worldview environment extends beyond water, land, and biodiversity, as there is inclusion of the following (to name only a few): spirit, ancestors, Creation Stories, teachings and the connection that Indigenous people have with the land - as a living being, living alongside each other, taking care of each other, depending on each other (2016, p. 26-35). I recognize the influence of my personal experiences and epistemology as it impacts and influences my relationship with Creation, and thus how I write a paper situated in exploring these relations. In recognizing this and defining the scope of 'environment' within this paper, I have attempted to apply a perspective which is appropriately reflective of what is identified by McGregor and the different aspects included when understanding 'environment' (2016, p. 26-35).

In their writing, Deborah McGregor (2016, p. 26-35) explores many of the core principles that are mentioned within several Indigenous community's worldviews. It is important to me that this paper does not generalize Indigenous worldviews as there is diversity within and between Nations, communities, and their practices (Hart, 2009b, p. 154). 
I feel a sense of caution in sharing specific stories and teachings as I write this paper, part of this is due to my lived experience and relation to and with these knowledges. I wonder if these are appropriate for me to share, and I think of the ways in which Indigenous worldviews and/or practices have been subjugated (Ineese-Nash, 2019, p. 6). McGregor (2016, pp. 26-35) outlines several principles pertaining to Indigenous relations with Creation. This relationship with Creation is understood within a worldview that references stories and teachings. McGregor's chapter is titled "All Our Relations: Aboriginal Perspectives on Environmental Issues in Canada" found in Visions of The Heart (McGregor, 2016, as cited in Long, \& Dickason, 2016). I encourage readers who may be interested in learning more about Indigenous worldview and values with the environment to read this chapter (McGregor, 2016).

For me, as a woman of mixed ancestry, and as a member of Six Nations of the Grand River, I was interested in specifically attending time to increase some of my learning and understandings of Haudenosaunee people's relations with the land from writings of Susan Hill's The Clay We are Made of: Haudenosaunee Land Tenure on The Grand River (2017). Hill shares and references several teachings from the "four epics of the Haudenosaunee" (2017, p. 7), along with reference to the Thanksgiving Address, and other aspects of Haudenosaunee worldview and ways of life. Referencing and learning from the writing of Haudenosaunee authors like Susan Hill (2017) is meaningful to me and my relation with Creation, as well as my understanding of the implications for my journey with research. This was meaningful as I was reflecting and developing my own understanding and relationship with the natural environment (most of which has taken place outside of a review of literature). Throughout my reading and learning from Indigenous sharers such as Susan Hill's application of Haudenosaunee worldview and the Four Epics, I have had meaningful reflection on the inherent connection between ourselves as humans, 
and the natural world which we experience and rely on, and thus must take care of, as it takes care of us (Hill, 2017).

Many of the articles I reviewed made reference to the important role the environment has within Indigenous culture and the interwoven nature of Indigenous worldview and wellness. This includes the wellbeing of the land being connected to individual and community wellbeing (Anderson, 2010; Freeman, 2019; McGregor, 2016; Isaak \& Marchessault, 2008, as cited in Tobias, \& Richmond, 2014, p. 26). Furthermore, a theme arose in the literature which included the understanding that for many folks, there is an important spiritual connection with the natural environment which relates to worldview and identity (Absolon, 2009; Anderson, 2010; Baskin, 2016; Freeman, 2019, p. 19; Hart, 2009; McGregor, 2004; McGregor, 2016; Richmond, 2018; Tobias \& Richmond, 2014; Wilson, 2008). In her conversations with Indigenous Grandmothers regarding their relations with water, Anderson (2010) identified the following: "What may be distinct about the Aboriginal Grandmothers' responses is that most of them also referred to the spiritual quality of water, and to the significance of this spirit in terms of creating and sustaining life" (2010, p. 7). These are just a few of the authors who speak of the inclusion of relations with the land as it relates to worldview and spirit. In my understanding of these articles and from my learnings within and outside of this search project, it is not just that relations with the land are $a$ part of worldview for many Indigenous folks, rather it can be of central importance.

\section{Indigenous Knowledges Related to the Natural Environment \& Considering Treatment of Indigenous Knowledges}

In recognizing some of the ways which Euro-centric research has been harmful to

Indigenous communities (as discussed earlier), it has been relevant and important for me to take space in learning some of the ways which research has/does take place within topics related to 
the environment and Indigenous Knowledges. Deborah McGregor (2004) speaks about the growing use of "Traditional Ecological Knowledges" (TEK) as it exists in academia. TEK relates to developing an understanding of the pre-existing knowledges held by many Indigenous people/communities about the environment (McGregor, 2004, p. 2). It is also worth noting that there have been challenges in establishing a shared understanding of TEK amongst different worldviews (McGregor, 2004, p. 396). McGregor identifies how the use and understanding of TEK has been promoted by non-Indigenous peoples as the world increasingly recognizes Indigenous folk's knowledges in environmental relations, and how this may assist with the global environmental crises (2004, p. 385). McGregor (2004) notes that while the use of TEK in Western research practices may have a more recent history, Traditional Indigenous Knowledges which encompass the environment have existed and been practiced for much longer (2004, p. 389). Writing from Brant Castellano (2016) too presents the prevalence of Indigenous knowledges being applied in different ways in contemporary settings by both Indigenous and non-Indigenous folks (p. 90). Brant Castellano (2016) further references Joe Couture with consideration of their contributions which have influenced the relevance of practices of learning and knowledges such as TEK (p. 91).

In my learning, I have also had the opportunity to considered the relevance in this learning of understandings of Two-Eyed Seeing (Marhsall, 2004 as cited by Bartlett, Marshall \& Marshall, 2012). Two-Eyed Seeing is a concept set forth by elders Albert Marshall, who is a Mi'kmaw elder (Bartlett, Marshall, \& Mashall, 2012). Two Eyed-Seeing speaks to an approach which exemplifies collaborative application and reference to ideas and knowing of Indigenous and non-Indigenous perspectives. Further, I have learned from writings to better understand values held within the conceptualization of Two-Eyed Seeing, which includes a collaboration to 
work together for the benefit of the future - as demonstrated by knowledge shared by elder Albert Marshall on page 336 (Bartlett, Marshall, Marshall, 2012). The learning and consideration of Two-Eyed Seeing is significant as I consider my role in this research, particularly as someone who has been raised in predominantly Euro-Centric ways, attempting to reconnect with culture in ways that are meaningful and appropriate for me on this journey.

McGregor shares their insights to which Indigenous understandings of TEK are situated in value and understanding of relations with Creation (2004, p. 386). McGregor speaks of the importance of learning and sharing where Indigenous Knowledges originate. McGregor states "Indigenous Knowledge comes from our relationship with Creation. In an Indigenous context, $\mathrm{ik}^{3}$ is by nature also environmental knowledge" (McGregor, 2004, p. 389).

In my reflection and learning from the writing of McGregor (2004) I have come to know of the importance of understanding, appreciating, and respecting how for many the ways which worldview and experiences connect to knowledge. It is also pertinent to consider how power influences the use and implementation of TEK within Euro-centric environmental practices (McGregor, 2004, p. 398-399). With this, I have learned of the ways which different types of knowledge can be treated (and related to) differently (specifically within reference to Eurocentric research and TEK) (McGregor, 2004, p. 397). This critical analysis (such as McGregor, 2004, pp. 398-399) sheds light on how TEK is presented and understood in mainstream research. This understanding presented by McGregor (2004, pp.398-399) further recognizes and identifies the ways power is involved with knowledges - which makes me think about epistemic injustice. Epistemic Injustice is the recognition of injustice within treatment and value of knowledges. The

${ }^{3}$ In this quote, McGregor uses "ik" in reference to Indigenous Knowledges (2004, p. 389). 
term Epistemic Injustice is recognized to be first used and described by philosopher Miranda Fricker (2007) (as cited in Tsosie, 2012, p. 1136). Understanding epistemic injustice within this context, I have considered the treatment of Indigenous knowledges by mainstream scholarship amongst the ongoing treatment of Indigenous communities, environmental racism, and sovereignty. Further, I consider the ways that land dispossession connects with Indigenous Knowledges, as issues related to access may pose threats to the continuation of Indigenous Knowledges related to the land for some individuals or communities (Centre for Indigenous Environmental Resources, 2005, as cited in McGregor, 2016, p. 40).

Hart (2009a) identifies the connection between colonialism and the treatment of Indigenous Knowledges. Hart references the following ways Indigenous Knowledges have been subjugated and treated poorly through various means and/or methods (Hart, 2009a, p. 27): "Indigenous knowledge, such as spirituality intertwined with the land are ignored." This speaks to some of the ways Indigenous environmental relations and knowledges have been subjugated. Further, Wildcat, McDonald, Irlbacher-Fox and Coulthard (2014) recognize the connection between settler colonialism and mistreatment of Indigenous Knowledges in their article specific to land-based education. Consider the following quote: "Settler-colonialism has functioned, in part, by deploying institutions of western education to undermine Indigenous intellectual development through cultural assimilation and the violent separation of Indigenous peoples from our sources of knowledge and strength - the land" (Wildcat et al., 2014, p. 2).

This review of literature does not express or represent the degree of knowledges that are held within Indigenous worldviews and by specific groups as the original stewards of the land that makes up Turtle Island. 


\section{Environmental Violence/Racism \& Dispossession on Turtle Island:}

While discussing and learning of Indigenous relations with the environment, it seems pertinent to explore the ways in which the environment is treated, particularly considering the writing which speaks about the treatment of the environment with relation to Indigenous jurisdiction, dispossession, and impacts of environmental violence and racism. Indigenous communities experience environmental violence and extraction of natural resources/contamination at alarmingly high levels (McGregor, 2016, p. 38). It is important to note that my understanding of environmental racism extends beyond the experiences of Indigenous communities, however, for the purposes of this project, I will focus on Indigenous peoples on Turtle Island. My learning of environmental racism is that which recognizes the disproportionate experiences of environmental injustice (and the various outcomes of such) which is experienced by people of colour (Johansen, 220, pp.1-2).

Considering the colonial state in which we exist on Turtle Island, McGregor (2016) identifies the importance of recognizing the impacts that actions of settlers have had on Indigenous individuals and communities, and how the consideration of historical happenings is "essential to understanding the current situation Aboriginal people face in relation to environmental governance in Canada and the reasons behind their efforts to re-establish relationships with their territories" (McGregor, 2016, p. 23).

Many of the articles I reviewed for this project recognized the negative impacts the environment is experiencing which have brought direct risks of health concerns, or impacts on the cultural wellbeing and/or lifestyle of Indigenous communities and individuals (Corntassel, \& Hardbarger, 2019, p. 88; Golden et al., 2015, p. 407; Freeman, 2019; Hoover, 2013; Tobias, \& Richmond, 2014). These negative impacts also include effects on wild life (Hoover, 2013). 
Additionally, Carroll, Garroutte, Noonan, and Buchwald also recognized connection between Indigenous health and the land (2018, p. 454). Articles by Anderson (2010), Hoover (2013), Tobias and Richmond (2014, p. 26) identified concerns involving contamination of natural resources within communities. Gosine and Teelucksingh (2008) also recognize the negative effects which Indigenous folks are experiencing in reference to the industry which interacts with the natural environment (as cited in Coates, 2013, p. 69). With the understanding of actions/activities/projects taking shape in environmentally harmful ways, non-Indigenous peoples are benefitting from the impacts of environmental violence (Agyeman et al., 2009, as cited in McGregor, 2016, p. 38).

Environmental violence and environmental dispossession from my learning may be understood as separate happenings and experiences; however, I recognize relatedness in these topics while reading as I understand them to often be led by industrial or colonial objectives or related systems/interacting systems. Dispossession recognizes a change in "access" to the natural environment (Richmond, 2018, p. 167). Further, Richmond recognizes these ongoing occurrences and impact of land dispossession in the following statement: "Since the onset of colonialism in North America, Canada's First Nations have endured centuries of environmental dispossession and cultural upheaval" (2018, p. 167). Richmond (2018, pp. 180-182) identifies how considerations of the land should be included in research and policy related to Indigenous peoples' health moving forward.

It is worth noting that a significant amount of research which speaks of environmental concern in response to climate crisis and/or impacts related to colonization (Golden et al., 2015; Hoover, 2013; Harper et al., 2012; Lowan-Trudeau, 2017; Lowan-Trudeau, 2019, Tobias \& Richmond, 2014). This dynamic will be referred to throughout this paper as I review the ways 
which environmental rights and traditional Indigenous knowledges may now be connected with the environmental movement and environmental justice ${ }^{4}$.

Several studies spoke of acts of resistance and/or resilience by Indigenous folks related to the land and water (Simpson, 2017, as cited in Corntassel, \& Hardbarger, 2019, p. 91; Golden et al., 2015; Lowan-Trudeau, 2017, p. 99-100; Richmond, 2018, p. 181; Tobias, \& Richmond, 2014, p. 28). Further, some articles land-based connections as a method of connecting with culture (Corntassel, \& Hardbarger, 2019, Freeman, 2019; Tobias, \& Richmond, 2014.). For me, it was important to recognize that this engagement with culture and resurgence through land/water protection may be taking place through resistance efforts which are involuntary (given responsibility which some folks may experience and/or carry) (McGregor, 2004, p. 388), and come with serious risks of reprisal from the colonial state and its' legal system (Crosby, \& Monaghan, 2018). Amongst this precarity, Indigenous land defenders exemplify resilience.

\section{Environmental Social work: What is it and Where is it in Practice?}

While this paper and topic is situated in learning from Indigenous sharers and authors, alongside consideration for environmental violence, I was curious to learn what literature exists from Western or Euro-centric perspectives related to this topic within social work. As a student in the field of social work, I wanted to learn how considerations of Indigenous knowledges and relations with land are or are not referenced in writing and practice. In my search efforts, I have

\footnotetext{
${ }^{4}$ Dominelli (2014) defines environmental injustice in their writing as the following:
} “society's failure to ensure the equitable distribution of the Earth's resources in meeting human needs, simultaneously providing for the well-being of people and planet Earth today and in the future" (p. 339). 
the opinion that this is a gap in the literature - particularly when considering the settler colonial roots within the profession, and ways social work interacts with 'reconciling' efforts.

Environmental social work, or 'green social work', is a growing topic and specialized focus of practice and advocacy (Dominelli, 2012, as cited in Androff, Fike, \& Rorke, 2017, p. 399). In learning about environmental social work, it is interesting to examine how this area of practice/advocacy developed and how understandings of person and environment consider, or do not consider, natural resources and the land with specific discussion of colonization on Turtle Island (Lawrence \& Dua, 2005, as cited in Hiller \& Carlson, 2018, p. 55-56). In their article, Hiller and Carlson (2018) critically discuss the different approaches to environmental social work. Further, they discuss the inclusion of environment within practice, what this relationship with environment might look like, and whether the frameworks of 'environmental social work' considers Indigenous environmental justice, sovereignty, and environmental violence .

One of the interests in my journey in this field of education is the influence and use of land and nature-based helping strategies within our practice. I have grown interested in finding ways which I may be able to incorporate land and nature into my practice as I recognize connection with the natural environment to have many helpful impacts and effects for my personal wellbeing. As discussed by Hiller and Carlson (2018), professionals under specific frameworks of environmental social work (such as “eco-spiritual approaches") sometimes incorporate nature and appreciation of/for the environment into practice - without learning the realities of the status of violence that is perpetuated against the environment, especially as it directly impacts Indigenous folks (2018, p. 58). Having a relationship with the environment and including this within practice is one component, but these authors problematize the ignorance of the status and/or lack of challenge to settler colonialism - which includes considerations for the 
unique ways Indigenous folks are impacted by the ongoing happenings on the land and water (Hiller \& Carlson, 2018).

In discussing the different approaches to environmental social work, environmental justice is the only framework reviewed by Hiller and Carlson (2018) in their writing which considers the influence and impact of colonialism on environmental justice. Their writing also critically considers the other systems and structures which impact the treatment and health of the environment (such as capitalism) (Dominelli, 2012, as cited in Hiller \& Carlson, 2018, p. 58). Coates (2013) highlights the relevance of these systems in relation to social work (as practiced in a settler colonial state) in the following statement:

This regime of production and consumption seeks profit without limits, separating human beings from nature, creating an arresting domination of the natural world, and transforming everything into commodities: water, earth, the human genome, ancestral cultures, biodiversity, justice, ethics, the rights of peoples, and life itself. (Coates, 2013, p. 66)

Additionally, with the growing conversations and movement of environmentalism, it is relevant to question if and when settler colonialism and Indigenous dispossession are included in this movement (Hiller \& Carlson, 2018, p. 53-54). Furthermore, as discussed by Hiller and Carlson, it is critical to also note the ways which 'environmentalism' can take shape in ways which include mistreatment and inappropriate claiming/relations with Indigenous Knowledges that do not prioritize respect of these knowledges in their entirety (Simpson, 2004, as cited in Hiller \& Carlson, 2018, p. 54). I reflect on this and the situation of this paper, with the hopes that this work has been done in an appropriate way, to prioritize Indigenous Knowledges and the 
ways which Indigenous lands are being violated in ways which I believe me/we - as learners in this field should be involved in dismantling as we critically reflect and make changes to our settlerhood - and what that means for each of us uniquely. Hiller and Carlson (2018) contend, "Without conscious efforts to interrogate and unsettle embedded colonial assumptions and relations, mainstream environmentalists can thus steamroll over the relationships of Indigenous peoples with their lands, as well as Indigenous people's efforts to repatriate their lands, maintain their ways of life, and disrupt and recover from colonial assaults" (2018, p. 54-55). I believe this is a significant quote as it offers a critical engagement with 'environmentalism' especially in terms of how it may or may not make space and consideration for the ways Indigenous land dispossession and violence is occurring. Hiller and Carlson suggest that "to ethically engage with environmentalism, social workers living and working on Indigenous territories must understand and resist settler colonialism, our implication in upholding its structure and practices, and its contribution to ecological destruction" (2018, p. 45). This article by Hiller and Carlson (2018), is written by self-identified non-Indigenous author/scholars, connects the topics of Indigenous sovereignty, land protection (amongst the occurrences of exploitative environmental practices), with social work practice situated on Turtle Island.

Based on my memory as a student who has been taking social work related postsecondary courses for 5 years, I do not recall significant mention of environmental considerations/land based relations in any of my mainstream social work classes - that is until graduate studies at Ryerson University. I had however learned of land-based practice and acknowledgement of relation between land and ourselves within Indigenous studies and/or classes which specifically consider Indigenous approaches to social work. 
In my reading I have also noticed Indigenous professionals in the field making reference to the natural environment and relation with land in their practice (Absolon, 2009; Baskin, 2016; Hart, 2009a). Absolon (2009) speaks of the ways in which the natural environment is involved in their practice, as a way to allow such elements be involved and support the process of healing: "During those times, I believe the elements such as the wind, water, earth, trees, animals and birds became the helpers and healers, and the environment's harmony fostered balance and healing within" (Absolon, 2009, p. 174). This connects to my learning as I consider ways which this topic relates to my development of practice and ways in which we take up practice and may be inclusionary of the land and water within practice.

The ways in which social work as a profession and social workers engage with environmental social work might look very different. Are social workers including environmental considerations and land-based relations into their practice? Are social workers allying themselves with Indigenous land and water protectors? To what degree or level are social workers willing to prioritize the protection and consideration of the environment into the work that they do as settlers on Turtle Island? These questions are further considered within the implications of this project. I am critical of myself and the ways I am not directly on the frontlines of this topic and issue as I write this paper from a position of great privilege with very little risk or threat. While I write this paper, it is also critical to consider the ways in which this topic has been represented within mainstream media amidst the resistance movements such as that of Coastal Gaslink in the Wet'suwet'en Territory (“All Eyes on Wet'suwet'en: International Call for Solidarity!", n.d.).

The political nature of this topic is intrinsic - I hope to situate this project as one which aligns with decolonizing approaches, and solidarity with the protection of Indigenous lands. I 
also note the caution of exploring this topic as it has been co-opted within discussions of environmentalism (Hiller \& Carlson, 2018, p. 58). I position this paper in considering the harm caused in the potential assumed innocence that is apparent in some approaches to this topic: "For settlers, these identifications involve extracting aspects of Indigeneity that allow us to reconnect emotionally and spiritually to the land while leaving unchallenged the power relations and practices that secure our own privileged claims to the land" (Hiller \& Carlson, 2018, p. 14). This further connects to the importance of acknowledging some of the unique experiences that some Indigenous folks may have in relation to this topic. Coates (2013) speaks to this in the following, "It is in the context of spirituality and the human relationship to the environment that Indigenous values, beliefs and practices find common ground, though from very different roots, with other ecospiritual approaches to social work theory and practice” (p. 67). Based on my learning, I would add to this quote by acknowledging the happenings and impacts of colonialism - the unique experiences which may impact access to environment, historical relationship with environment/space, and contemporary happenings ${ }^{5}$. I have reflected on the ways which different approaches to practice which include the environment do, or do not, address or seek to challenge colonial structures or systems.

\section{Methodology}

Search and 'selection' of methodology was an ongoing and thoughtful process. As a young person who has been raised exclusively in Western education, my understanding of research and methodology prior to this program has been significantly influenced by Euro-Western ideas of

\footnotetext{
${ }^{5}$ Inclusion of historical considerations was later identified by Coates (2013, p. 72).
} 
such. Early on in this journey of research I had recognized that my project would not take place through interviewing or through conversation (interviews, sharing circles, surveys) with other folks - as I was unsure of my capacity to complete this project within timeline parameters in a way which felt respectful of my current place and space of learning. As someone who has very little experience in research, and no previous experience/learning specifically with Indigenous Research Paradigms - I felt I needed to recognize where I am situated in the journey of learning and work from a primarily text-based approach.

I have spent a significant amount of time throughout this process learning more about Indigenous research frameworks, and thus, what may be included within an Indigenous methodology. In learning from and reading the works of Kathy Absolon (2011), I began to explore how my journey of searching could be a more wholistic approach - encouraging my learning and writing as a searcher. I had been locating articles and books to read and apply critical thought - but had not yet attended to other areas of my being and learning which would connect to the work of this project. As a woman of mixed-ancestry, I was unsure of ways to engage with this aspect of my personal culture and worldview in an appropriate and respectful way.

The implementation of a text-based research analysis was an intentional and purposeful choice made throughout the process of this MRP. I see the choice of operationalizing secondary research (of publicly available documents-online) as my chosen methodology as a form of resistance. Further, with epistemic injustice as a consideration in this paper, I have chosen to highlight the knowledges which Indigenous folks have written about with regards to the land and environment. Absolon (2011) offers the following insights into Indigenous methodologies: "The sooner the academy recognizes the existence and validity of Indigenous methodologies, the 
closer the academy comes to creating a welcoming environment for Indigenous scholars, who can then focus their energy on all areas of Indigenous knowledge production” (p. 47). While I recognize the use of text-based methodology is not exclusively an Indigenous methodology, I will explore the ways in which I have attempted to approach this project in more wholistic ways.

Hart (2009b) speaks about an Indigenous research paradigm which involves the researcher and functions with accountability for their relations (Wilson, 2001, as cited in Hart, 2009b, p. 157-158). This focus on accountability has informed my choice to complete secondary research (text-based) - by including myself within the search, and seeking to hold my relations accountable, while also recognizing my own capacity and space in relationship to academic research.

Within the text-based research, I have chosen to discuss my learning in themes which are seemingly relevant to social work practice. The report selected for the purposes of learning (application of methodology) is Land Back: A Yellowhead Institute Red Paper (King \& Pasternak, 2019). While there are other text-based analysis methodologies which I have learned about and considered applying to this research, I have chosen the Kaandossiwin and the Petal Flower Framework, and my learnings from such to inform my research journey (Absolon, 2011, p. 47-52). Absolon (2011) notes that similar to how we depend on the natural environment, the flower depends on the world around it to flourish (p. 49). The framework includes various aspects within a flower which are representative of the different areas of this wholistic methodology (Absolon, 2011, p. 47-52). The recognition of environmental impact within my own research journey did influence a shift in this process of learning as I addressed other areas and ways to support my growth and learning -such as my spirit. I have depended on the different parts of the Petal Flower Framework to engage with this journey of learning and writing. The 
framework includes consideration of various areas of life and the journey of engaging in research.

The Petal Flower Framework presented by Absolon (2011) feels appropriate and it is important that I identify the different components of the Petal Flower framework. I will now go through the different parts of The Petal Framework (Absolon, 2011) and identify the different areas of the framework (as presented by Absolon, 2011) as they relate to my method for this project.

\section{"The Roots" (Absolon, 2011, pp. 53-66 )}

Absolon references the roots of the Petal Flower Framework as being connected to "worldview" and "paradigm" through which someone experiences the world (2011, p. 50). This is influenced by the worldview of the person who is engaging in the research (Absolon, 2011). As identified earlier, as a woman of mixed ancestry, I experience the world in ways which are informed by both Indigenous and non-Indigenous worldviews. As someone who was not raised with traditional knowledges or practices of Haudenosaunee people, I believe my worldview and roots are ever-changing as I attempt to decolonize some of my understandings.

\section{"The Centre of the Flower" (Absolon, 2011, pp. 67-84)}

The centre of the flower suggests that a researcher is aware of and consciously refers to themselves in their search. Some may see this as the location of oneself into the project. For me, this is a recognition of who I am, what experiences I have or have not had and what knowledges I do or do not have. As Absolon (2011) explains, "Our knowledge is ultimately what we have when we are on our search" (p. 70). I have centered myself in this search by locating my experiences, and ways which I have come to the place I am currently. As will be discussed later, I have situated my research within a space of and for learning. With this, I intend on situating 
myself in the implications of this search as I discuss what I have learned, and what this means for me moving forward.

\section{“The Leaves: The Methodological Journey: (Absolon, 2011, pp. 85-95)}

As discussed earlier, my process of learning and unlearning about research, particularly research with Indigenous folks has changed throughout the duration of this project. Part of this journey was coming to understand what meaningful research may mean to me, and what that may mean for me within this place of my life.

What might appropriate research mean to me? What are my limitations? What is realistic for me to do? The journey began with wondering about my knowledge and at times, insecurity. The journey was education, sharing my thoughts with others (peers, professors, mentors, family), and ultimately leaning into the space of curiosity to develop ideas for the questions I had about the process. The journey involved my learning about well publicized direct action and land defence of Indigenous folks across Turtle Island, and non-Indigenous allies. The journey involved an observation of all of this - a very privileged position I note. This journey involved learning more about realities which are not my own, and learning about realities which do impact me; wondering how a paper will propel movement towards 'justice' for the issue of environmental violence? This thought has particularly been relevant as I have learned of direct actions which strive for justice. The journey involved decision making, or space for comfort with unanswered questions. After having gone through this journey, I recognize the prevalence of writing presented by Hart (2009a, p. 163) in which "self-reflection" is presented within the research experience which resonates to me as I ponder my changing comfort within and throughout this journey. The journey involved unexpected changes. The journey involved grief and challenges of a global pandemic. Particularly with considering and learning of 
environmental racism, it has been significant to also critically learn, unlearn, engage, and critically reflect on my understandings of broader systems of racism. The journey also brought me home, meaning making, and involved time and space to learn about my spirit.

Absolon (2011, p. 91) speaks about transformation in the journey within this part of the framework. While this project may not be transformative in creating social change, or change for others, it was transformative for the way I engage with learning. Namely, learning about Indigenous research and furthering my understanding of relations with Creation from the writing and sharing of Indigenous folks is what made this process transformative and meaningful to me.

\section{"The Stem: Backbone and Supports" (Absolon, 2011, pp. 96-117)}

The stem represents what holds you up as a researcher - what are the supports to my search? An ongoing support throughout my research journey and throughout education has been a motivation to learn and move towards decolonizing social work in meaningful ways. Motivation in hopes of broadening my learning and responsibility.

I had support from family, friends, mentors, and peers throughout my journey. I have felt supported by faculty from Ryerson University to make this process meaningful and appropriate for me. Resistance to the dominant ways of research is uncomfortable at times. I have felt support from reading the writing of other Indigenous researchers.

\section{"The Petals: Diverse Methodologies" (Absolon, 2011, pp. 118-139)}

Absolon (2011) recognizes the use and space for "allied theories" within Indigenous research projects and efforts (p.148-150). I recognize the influence and learning I have had from reading the writings of others and making peace with the methodology of my project with respect to the goals and ethics which I hope to keep in the forefront of this project. At the beginning of this journey when I knew I would be engaging in secondary-research (for reasons 
already discussed) I thought I might use a methodology primarily informed by Critical Discourse Analysis (CDA) (Wodak, \& Meyer, 2001). I had reflected on a few ways which this specific approach may have limitations for this project. There are aspects of CDA which are appealing to my interests and positioning of this search such as the ways in which power can be critically discussed with reference to structures (Fairclough \& Kress, 1993, as cited in Wodak, \& Meyer, 2001, p. 3). However, I see limitations in this project (MRP) specifically by looking at the language or rhetoric. First, in my understanding of CDA, I see the researcher as someone who is specifically learning about the rhetoric surrounding an idea or social issue (Wodak, \& Meyer, 2001). This feels inappropriate to this specific project's scope and topic as I am not specifically focussing on rhetoric or the discussion related to this topic - alternatively, I have the belief and understanding that Indigenous folks have been talking and representing ideas surrounding knowledges of and with the land, and relations amongst settler colonialism for a long period of time and it is pertinent to learn from these writings and narratives. Instead of approaching this work from a perspective of analysis, I have chosen to approach this text-based methodology as a sharing of my learning and 'take aways'. This was also important for me as I situate myself ethically in this search - and wanting to avoid generalizations of what I have shared and discussed. While I believe there is space for critical analysis within this project, the goal of my search is not to analyze other folks' written materials - but rather to engage in learning and discussing ways which this learning is relevant to my journey personally and within this field of work.

While reading the reviewed material, I contemplated and reflected upon the following questions (guided by my perspective):

- What issues and topics (themes) are being represented in this writing? 
- How does this connect to decolonizing social work?

- How does this interact and connect with anti-colonial and Indigenous theory? (referring back to the theoretical framework of this paper)

- How does this writing connect with the research and literature I have found along the journey of this project?

As represented in a visual on page 119 in Kaandossiwin, Absolon (2011) identifies different activities and considerations which connect with a methodology which someone may be using within their search journey. For me, this was an important realization. While my methodology includes the use of secondary analysis, there is more involved with this - hence the framework acknowledging these different aspects which impact the process. This includes identifying body, spirit, mind, and heart (Absolon, 2011, p. 119). Here are a few of the actions that I have engaged with to support my methodology and conversation with the material referenced later in this text:

- During this process, I have had the opportunity to return home, to the space I was raised and where I first began learning. In various ways, coming to this place has represented reconnection with space that represents home for me. While at home, I have spent significant time outside. I reflect on ways this was meaningful as I considered the topic of this project and my privilege.

- During this time, I have engaged in learning more about Haudenosaunee worldview and culture. This has included reading about Haudenosaunee Creation story and ways which Haudenosaunee people have traditionally engaged with the lands. This learning was personal. 
- I have intentionally spent time unlearning and learning ways which Indigenous research may take space - reading from authors who have written about their relationship with research (Absolon, 2011; Hart, 2009a; Hart, 2009b; Wilson, 2008). With this, I have learned the importance of centering Indigenous Knowledges, and an anti-colonial stance within this project.

I believe that my engagement with these activities contributed to my understanding, and thus my methodology of textual analysis.

Lastly, I note a limitation of my employed methodology which pertains to relations with others. I do see a limitation of this research in the lack of relationships I have gained with others by choosing to complete secondary research, rather than primary research. I reflect on the importance of this relational aspect within the writings of Indigenous scholars (Weber-Pillwax, 2001, as cited in Hart, 2009a, p. 159; Wilson, 2008, p. 43;).

As noted earlier, it is important to note my privilege and situation in relation to this topic as I write about and learn from experiences of resistance with little risk of repercussion to my daily life and safety. This work is political as spoken about by Hart (2009b):

Research is a political act whether we want it to be or not. When we choose how we are going to come to know, meaning when we pick up a research methodology, we are privileging particular ways-of-being in the world. (p. 168)

This research paper is not to be framed as an ideal way of searching, rather I see this path as the one which supports my needs and capacity, and feels most appropriate given the context of completing this research. The process of decision making throughout this journey has at times felt uncomfortable and uneasy. I reflect on how this may be part of decolonizing my own mind 
and experience, as Tuck and Yang $(2012$, p. 3) reference such feelings. This is my first attempt at engaging with the journey of research in such a format. I am hopeful that in the future I will have opportunity to engage in research in a way which is more contributory and reciprocal to supporting individuals and communities.

Lastly, within this method of search and my learning from reading the "Tri-Council Policy Statement : Ethical Conduct for Research Involving Humans - TCPS 2 (2018)" "Chapter 9: Research Involving the First Nations, Inuit and Metis Peoples of Canada", I have the understanding that this project does not require application to the Ryerson REB (article 2.2) (“TCPS 2 (2018) - Chapter 9: Research Involving the First Nations, Inuit and Métis Peoples of Canada", 2019).

\section{Data Collection}

In line with what is commonly referred to as a secondary research approach, I have chosen to discuss areas of a report prepared by King and Pasternak (2019) which is titled, Land Back: A Yellowhead Institute red paper. This paper is published in Toronto by the Yellowhead Institute.

In hopes of transparency, and recognition of the ways which this project has existed in a journey, I did originally hope to review materials from more authors for the purposes of this MRP. Given changes throughout this process, I had changed my goal to include the textual analysis and learning of the Land Back: A Yellowhead Institute Red Paper. After reviewing the literature discussed and engaging in the journey thus far - I feel it is pertinent for me to learn more about Indigenous land jurisdiction. This is important as someone who is interested in environmental justice and decolonizing social work; I have chosen to follow up with this in my collection of material and with the duration of this project. 
Given the outline of the methodology I am applying to this project, the discussion I provide related to the literature exists as one interpretation of the writing and themes which emerged for myself while reading and learning. In thinking about this, I have reflected on learning which I gathered from reading about locating oneself from Absolon (2009), which includes the following: "Location also establishes who I am not. I only represent myself and my experiences and do not speak on behalf of all Indigenous people" (Absolon, 2009, p. 173). Within my methodology I hope to have recognized who I am, and with that - what insights or limitations I may have in relation to this writing. This is particularly important for me to note as I recognize that the material chosen in 'data collection' speaks to a degree of legal frameworks and logistics which I do not have education or experience with (Indigenous law and settler legal frameworks). Rather, I see this as an important opportunity to engage in learning about environmental dispossession and treatment of lands and water as it relates to ways of decolonizing social work for me.

Lastly, I hope to speak to my capacity and limitations as I recognize them given that Land Back: A Yellowhead Institute Red Paper (King \& Pasternak, 2019) is 68 pages in length, and given the parameters of this research project, I do not attempt to provide a comprehensive analysis of the entire document. Instead, I focus on the main ideas which resonated with me in relation to the questions listed previously - as one perspective guided by my personal lived experience, and my learning from the theoretical framework identified, and the reviewed literature. Lastly, this is not to reduce my responsibility or accountability, but I recognize that within my educational experience and background, I have not had significant learning related to land dispossession, jurisdiction or land-based relations; as such my interpretation of the Land Back: A Yellowhead Institute Red Paper (King \& Pasternak, 2019) is one which reflects my 
educational background and potential limitations. This returns to the idea which reconigzes this project is a way for to me to learn and grow. I reflect on how my limitations of understanding related to land jurisdiction highlight how I must learn and grow, and attempt to better understand my role as a person of mixed ancestry.

Within the situation of my interpretation of Land Back: A Yellowhead Institute Red Paper (King \& Pasternak, 2019), it identifies examples and ways which Indigenous jurisdiction of lands has and continues to take place in the settler colonial state with reference to Canadian policy. Further, the authors discuss several of the impacts of these happenings, while also identifying the ongoing resistance efforts by Indigenous individuals and communities (King \& Pasternak, 2019). In reading of this report, I have reflected on the ways it has helped me increase practical knowledges of historical and current Canadian policy/legal processes which involve land dispossession - with primary focus on consent, while also identifying impacts of these processes and some ways which resistance has occurred within/by communities.

\section{Learning from Writing and a Conversation of Learning:}

\section{“Land Back: A Yellowhead Institute Red Paper" (King \& Pasternak, 2019)}

Land Back: A Yellowhead Institute Red Paper (King \& Pasternak, 2019) is a report published by the Yellowhead Institute in fall of 2019. The report is situated to address the realities of Indigenous land dispossession and jurisdiction in what is known as Canada by incorporating history and current realities of the land alienation, processes of the legal system, industries, and the system of settler colonialism. While identifying concepts and examples of ways which land jurisdiction takes place/has taken place, the report also identifies examples of Indigenous communities that have strategically acted in resistance in defence of their land and 
waters (King \& Pasternak, 2019, p. 6). Throughout the report, sections are separated to identify and discuss ways which the "spectrum of consent" takes place, with reference to examples of happenings within Indigenous communities (King \& Pasternak, 2019, p. 16).

\section{Connected Systems \& Structures}

A major learning for myself after reading Land Back: A Yellowhead Institute Red Paper was the ways which historical systems or "social institutions" (p. 16) which represent actions guided by colonial agendas connect to the dispossession and jurisdiction of lands. I understood this idea in learning from "Infrastructure of Theft" (King \& Pasternak, 2019, p. 16) as there were many ways which this was employed through colonial acts and systems. Further, this allowed me to have consideration for ways which land dispossession and land jurisdiction connect to the experiences of colonial legacies which I have been learning about within my studies in social work. While I had understood concepts which informed me of the relationship between these systems - such as the writing of Tuck and Yang (2012) related to settler colonialism, my learning from Land Back: A Yellowhead Red Paper (King \& Pasternak, 2019), increased this understanding as I have a more practical understanding of examples of ways which this has taken place/shape with relation to land jurisdiction and dispossession specifically.

Further, significant learning was in understanding some of the ways which structures in Canada (economically) connect to the systems associated with natural resources ${ }^{6}\left(\mathrm{King}_{\mathrm{B}}\right.$ Pasternak, 2019).

In learning a part of this topic which I had not yet before explored, I have increased understanding of some of the processes and structures related to the industries which are

\footnotetext{
${ }^{6}$ From my interpretation of Land Back: A Yellowhead Institute Red Paper I saw this reflected on page 10, and on pages 25-26 (King \& Pasternak, 2019).
} 
involved with development or extraction efforts on First Nations communities. As mentioned earlier, I cannot pretend to comprehensively, represent the writing within Land Back: A Yellowhead Institute Red Paper (King \& Pasternak, 2019) in it's entirety given some of the legal specifics which I am not educated on. Rather, I can better appreciate how the report identified the ways which these structures may often support industry agendas and/or goals. To me, one example of this was reflected on page 10 of Land Back: A Yellowhead Institute Red Paper, where the authors discuss the influence which the system of natural resource sector has within the Canadian economy (King \& Pasternak, 2019). This assisted me with comprehending the ways which these systems seem to be very interwoven within the settler state.

Additionally, considerations of the status of the environment (climate change and degradation) are included within Land Back: A Yellowhead Institute Red Paper ${ }^{7}$ (King \& Pasternak, 2019). I reflect on how this may be considered (or not considered) within the structures and systems while it is evident to our realities. Consider the following: “...the life of our species and of the planet are at risk from the type of economic philosophy and practices of perpetuated by colonialism and settler colonialism” (King \& Pasternak, 2019, p. 64).

\section{Consent and Self-Determination}

Consent and self-determination to me are different concepts, not to be confused for one another- but I do see some overlapping ideas. For example, both concepts present the importance of being led by Indigenous individuals/communities. I begin this section of writing recognizing that the 'idea' of reiterating the importance of Indigenous self-determination is not new learning for me - however this was thoroughly discussed throughout Land Back: A Yellowhead Institute

${ }^{7}$ From my learning, I have recognized reference to this concept on pages 12, 60, 64, and 65 (King \& Pasternak, 2019). 
Red Paper (King \& Pasternak, 2019) and it felt important to represent and discuss the relevance of this as I consider this project and my relation with professional practice moving forward.

Consent is discussed and presented throughout Land Back: A Yellowhead Institute Red Paper in several ways (King \& Pasternak, 2019). The paper references the ways which consent with land jurisdiction and dispossession has and continues to exist along a "spectrum" (King \& Pasternak, 2019, p. 16). Presented as a spectrum, the authors identify consent related to land jurisdiction and dispossession to exist in forms of denial, recognition, and reclamation (King \& Pasternak, 2019, p. 8). Further, the authors assert that these different understandings and approaches to consent exist due to "competing conceptions of consent" (King \& Pasternak, 2019, p. 9). In reference to reclamation, the authors also identified ways which "consent-based efforts" may take place beyond the involvement of the Crown (King \& Pasternak, 2019, p. 48).

I reflect on the ways consent may be a complicated topic to explore when broadly considering happenings of the ongoing colonization of Turtle Island, and more specifically, what is considered to be Canada. While this theme of learning was not necessarily new to me, it reaffirmed the importance of Indigenous self-determination. On page 9 and page 21 of Land Back: A Yellowhead Institute Red Paper, the authors identified a framework which represents four main concepts and principles which may be helpful when considering Indigenous consent (King \& Pasternak, 2019). This also included recognition of the use of "FPIC" - Free, Prior, Informed Consent (King \& Pasternak, 2019, p. 20). One of the four main ideas mentioned within the presented framework was “epistemology"8 (King \& Pasternak, 2019, p. 9). With this, the

\footnotetext{
${ }^{8}$ I had noted the reference to "epistemology" found on both page 9 and 21 within Land Back: A
} Yellowhead Institute Red Paper (King \& Pasternak, 2019). 
pertinence of the treatment of knowledges as valid, important, and necessary - again connecting back to ideas discussed in this project (MRP) related to justice and epistemology. This makes me reflect on the ways which there is a "dichotomy" in understanding and research practices when considering TEK (as discussed in literature reviewed earlier) (McGregor, 2004, p. 386). In reading and learning of the different ways which consent takes place (or does not) in regards to Indigenous land jurisdiction, development/extractive projects, and the impacts of these projects the report prioritized and re-affirmed the importance of consent being led by Indigenous individuals and that a community's priorities be considered - such as being led within worldview (i.e., Indigenous law) ${ }^{9}$ (King \& Pasternak, 2019). The authors raise awareness of how "harm" is determined and understood (and how this can vary) (p. 41). To me, this connects back to some of the earlier learning in this project related to justice associated to epistemology, and as such, the treatment of different knowledges.

Notably, within the report - the authors identify that the positioning of the report is not to suggest the erasure of all activities related to natural resources, rather prioritizing these decisions being made at a community level (King \& Pasternak, 2019, p. 12). To me, this connects back to self-determination and consent.

When considering self-determination related to land jurisdiction, the following quote resonated with me and my learning: "The point is that Indigenous people make those decisions, enforce them in their territories, and have them respected by outsiders. This is the crux of jurisdiction" (King \& Pasternak, 2019, p. 60). Further, the authors present and support the importance of decisions and choices being made “...on their own terms" (King \& Pasternak,

${ }^{9}$ From my interpretation, I noted that this reflected on page 9 and page 21 (King \& Pasternak, 2019). 
2019, p. 6). This is in reference to the ways which communities "respond to federal plans on their own terms" (King \& Pasternak, 2019, p. 6). This quote in particular resonated with me because it is a seemingly simple idea, but represents significant importance and is not simple when considering the implications of colonialism and operating systems which govern these processes. While discussed in a different context and perspective, the "exclusion from environmental decision-making" was also discussed in previously reviewed literature from McGregor (2016 p. 39). This further reflects the importance of self-determination and meaningful engagement with these decisions. I also reflect on a limitation of my search as I have not thoroughly reviewed concepts related to Indigenous law which relates to land jurisdiction and what may be involved with this (King \& Pasternak, 2019, p. 17).

\section{Indigenous Knowledges, Decision-Making \& Considerations of the Climate Crisis}

Worth noting are the ways in which the authors of Land Back: A Yellowhead Institute Red Paper recognize the knowledges held by many First Nations communities and individuals related to the land and water - and protection/sustainability of $\operatorname{such}^{10}$ (King \& Pasternak, 2019). "So the matter of land back is not merely a matter of justice, rights or "reconciliation"; Indigenous jurisdiction can indeed help mitigate the loss of biodiversity and climate crisis" (King \& Pasternak, 2019, p. 64). I reflect on the relevance of this considering literature reviewed earlier - such as learning from Golden et al. (2015, p. 410), which discussed the contributions of Indigenous folks' knowledges amongst the ongoing climate crisis. While the report acknowledges the ways which many Indigenous folks have historically (and many individuals

${ }^{10}$ I have noted this referenced on the following pages of Land Back: A Yellowhead Institute Red Paper: 12, 64 (King \& Pasternak, 2019). 
and communities presently) practiced sustainable efforts ${ }^{11}$, I also reflect on the ways which the writing within Land Back: A Yellowhead Institute Red Paper also does not generalize that all Indigenous individuals or communities' perceptions of development projects altogether - rather, I learned of the ways which this is independent on each community (as presented on page 12) and with this, the importance of consent processes (which may also act as a way to support the defense of the ongoing climate crisis as discussed on page 60) (King \& Pasternak, 2019). From my understanding and reading of Land Back: A Yellowhead Institute Red Paper, I have reflected on how this is captured in the following quote from King and Pasternak (2019): "While it is no doubt that some communities support and participate in development that may be ecologically unsound, the principles of consent-based jurisdiction offer an important opportunity for addressing biodiversity loss and mitigating climate change" (King \& Pasternak, 2019, p. 60). For me, this identified the importance of self-determination of Indigenous knowledges within the evolving understandings and movements addressing the ongoing climate crisis. Further, to me this is a recognition of the nuances (as a way of recognizing the potential for different experiences and practices), while also valuing the knowledges held by many Indigenous communities regarding the relationship and caretaking of the land and environment.

\section{Considering Colonial Dynamics of Gender}

While reading Land Back: A Yellowhead Institute Red Paper (King \& Pasternak, 2019), I noticed a theme which identified a connection between the topic of environmental violence and protection, as it connects to the legacy and dynamics of gender within settler colonialism. Indeed, the authors recognize the pertinence of including a gender analysis to this topic: "Land and water alienation must also be understood through gender dynamics. Which are instrumental

${ }^{11}$ I have noted that "sustainable" practices were discussed on page 64 (King \& Pasternak, 2019). 
to how land loss and dispossession unfold and impact people's lives" (King \& Pasternak, 2019, p. 10). Land Back: A Yellowhead Institute Red Paper, discusses several examples of ways which gender and patriarchy has impacted the lives of many women, girls, Two-Spirit, Queer and gender diverse folks ${ }^{12}$ (King \& Pasternak, 2019). Additionally noted, the authors referenced gender-dynamics in relation to negative impacts on reproductive health (King \& Pasternak, p. 32).

Further, the authors discuss some of the ways how patriarchy has been connected and influenced processes and practices related to land jurisdiction (King \& Pasternak, 2019, p. 27). Also referenced within the Land Back: A Yellowhead Institute Red Paper, are noted concerns related to some of the common happenings and/or processes (resulting from development or extraction projects) which raise concern to high rates of violence ("Women's Declaration Against Man Camps”, 2017, as cited in King \& Pasternak, 2019, p. 29),

Again, this is a notable learning as I come to understand the deep-rooted nature in which these systems and structures are connected and interact. For me, particularly as a woman of mixed Indigenous background, the analysis and consideration of the impacts of gender feels of great significance. I recognize the privilege and power of learning about this connection through reading a report - as someone who does not perceive my daily experiences to be impacted by environmental injustice our direct impacts of dispossession. Prior to reading this report, I had understandings and recognition of some of the ways which Indigenous women, girls, and TwoSpirit folks experience violence and trauma at highly unjust rates (Palmateer, 2016), but I had

12 I have noted the reference to this (and related concepts) found within Land Back: A Yellowhead Institute Red Paper (King \& Pasternak, 2019) on the following pages: 10, 26, $27,32$. 
not understood how the relations of land jurisdiction and environmental violence were so connected to patriarchal ideas and structures (King \& Pasternak, 2019, p. 10).

After learning more about this connection (gender and environmental violence) from Land Back: A Yellowhead Institute Red Paper (King \& Pasternak, 2019), and considering some of the implications of this connection, I was able to learn of other authors who speak to this connection. In an article written by Waldron (2018), considerable thought and analysis is applied to the ways which Indigenous and Black women in Canada experience and are impacted by environmental violence in unique ways. Further, the Women's Earth Alliance and Native Youth Sexual Health Network identified the connection and prevalence of women and girl's experiences with violence and harm related to the ongoing actions of resource extraction, with consideration for the broader happenings within colonialism (Konsmo \& Kahealani Pacheco, 2016, p. 9). This report titled, "Violence on the Land's Violence on Our Bodies" discusses the connections of dynamics related to gender in greater detail and was referenced within Land Back: A Yellowhead Institute Red Paper (Konsmo \& Kahealani Pacheco 2016, as cited in King \& Pasternak, 2019, p.27). In reflection of literature reviewed earlier in this journey, issues of violence against women and girls and impacts of the patriarchy were also discussed by Wildcat et al. (2014, p. 10). Also identified within the report are the ways and degree to which women and Two-Spirit folks may often be involved in leading environmental efforts and protection (King \& Pasternak, 2019, p. 33). This further identifies the importance of an understanding of these issues with a consideration of unique experiences of different intersections of identity, and actions related to this topic.

When we discuss or hear about happenings such as developments which pose risk to the lands, do we also consider the direct harm and violence this causes to individuals, families, and communities? Do we consider the ways which patriarchy and settler colonialism have influenced 
how we subjugate the land and along with that, how these systems/structures affect women, girls, gender-diverse folx, queer, trans, and Two-Spirit people?

With this sub-topic being noted, I do reflect on a limitation of this project as I had not thoroughly discussed or reviewed writing which specifically incorporates a feminist lens or theory to this topic and more specifically, of the ways which these topics are related. While I do not believe I have space/capacity within this project to further discuss these related ideas of Indigenous Feminism - I see this as relevant for further learning (see Arvin, Tuck, \& Morrill, 2013; Waldron, 2018). Rather, I do hope that by discussing this pertinent dynamic (directly related to the wellbeing of folks), I may be able to more critically consider the potential impacts on Indigenous folks, and moreover better understand these dynamics when advocating for justice. Further, this represents the urgent need for change to address the crisis in which Indigenous women, girls, and Two-Spirit people are experiencing violence. I believe that when we seek to address and respond to this crisis of violence (perpetuated by levels of structures and systems as a result of settler colonialism) it is relevant to consider the growing recognition of "gender-based environmental violence" (Carmen \& Waghiyi, 2012, as cited in Konsmo \& Kahealani Pacheco, 2016, p. 13), treatment of the lands, and ways that the current system of resource extraction and develop directly cause harm to Indigenous folks - with consideration of gender dynamics and the patriarchy.

\section{Resistance}

Actions and efforts of resistance are not necessarily new understanding for my learning, rather I was able to learn of specific examples of resistance within Land Back: A Yellowhead Red Paper (King \& Pasternak, 2019). Furthermore, within the report, the authors discuss several efforts and strategies that First Nations communities have employed in defense of land and waters (King \& Pasternak, 2019). In the introduction of the report, the long history of 
Indigenous resistance is recognized with specific reference to the Original Red Paper, which was a direct response to Pierre Trudeau's White Paper in 1960 (King \& Pasternak, 2019, p. 6). I share this as I reflect on the importance of learning of the histories of resistance as I begin to better understand these contemporary actions of land and water defence.

Further, with recognition of the original Red Paper, Land Back: A Yellowhead Institute Red Paper situates Indigenous resistance as an ongoing happening (King \& Pasternak, 2019, p. 8). Consider the following quote: "This change must begin on the ground: Canada ceding real jurisdiction to Indigenous peoples for this transformation to happen. With or without Canadians, Indigenous people will continue to exercise it because responsibility demands it" (King \& Pasternak, 2019, p. 8). Further, in considering the ways that the report looks at some of the different ways which consent may take place, I believe resistance efforts can be represented in all sections of the report - with significant writing which represented resistance within "Section Four: Reclamation" (King \& Pasternak, 2019, pp. 47-61). Such examples and understandings are identified by the authors as "Taken together, they inform a general framework Indigenous-led consent processes." (King \& Pasternak, 2019, p. 48). Learning about these examples of intentional actions and ways of leading Indigenous-led consent was practically helpful to my understanding of ways which these actions and efforts take place (with significant intentionality).

There are various resistance efforts which are identified within Land Back: A Yellowhead Institute Red Paper (King \& Pasternak, 2019) in which communities have employed specific efforts and strategies to resist actions/resulting impacts related to the land and water. As identified earlier, this project is not intended to provide a summary of Land Back: A Yellowhead Institute Red Paper, rather a conversation of ways which I have learned from this writing in consideration of the questions listed earlier, and as I consider my role and actions in decolonizing 
social work. When considering the resistance efforts identified within Land Back: A Yellowhead Institute Red Paper, I reflect on ways which I recognize some resistance efforts are supported, or not supported by government or other groups. And further, I question how these efforts are taken up within the spaces of social work. In learning about the significant impact of colonial systems impacting the land and the degree to which this system directly causes harm to Indigenous folks specifically, it is important to also recognize the ongoing resistance to these systems and structures. A quote that reflected this to me was the following: "That is not to say that Indigenous people have universally, or willingly, accepted this state of affairs" (King \& Pasternak, 2019, p. 48). Further, I am engaging in critical questioning of the ways that I understand and shape efforts of 'resistance' given the ways which folk's lives have been implicated by the Canadian legal system. On page 58 of Land Back: A Yellowhead Institute Red Paper (King \& Pasternak, 2019), the authors speak of happenings at Unist'ot'en in 2018 which resulted in folks being arrested. I recognize a limitation in this research process as I have not thoroughly engaged with making sense and/or problematizing the ways which Indigenous efforts of resistance related to land jurisdiction and dispossession may often involve the Canadian legal system and potential repercussions of such. I am aware of this and want to name the ways which this paper (MRP) is situated in a privileged position with relation to these ongoing efforts and actions.

Further, I recognize that efforts which I have situated as 'resistance' may also be representative of engagement and intentional action to reclaim and reoccupy spaces and cultural practices. This was presented on page 58-59 amongst discussion of happenings with Nimkii Aazhibikong camp which was guided by envisioning of elders (King \& Pasternak, 2019, p. 5859). In my understanding and reflection, resistance, and ways which these efforts are represented, and discussed is critical, and highly political. I have reflected on this with increased 
cognizance as I have not included any significant consideration of literature (within this paper) which speaks to ways resistance is responded to by media, public opinion, and particularly by law enforcement. As I have not focused on unpacking and unsettling of the ways which these representations take place/shape (i.e., through media), I regard this as a limitation of my MRP.

\section{Asking Questions \& Going Further}

In this section, I reflect on critical questions I had noted from the authors writing within Land Back: A Yellowhead Institute Red Paper (King \& Pasternak, 2019). I have also recognized questions that have emerged from my writing, and reflections. I have considered the ways which questions have been presented and prompted thought related to issues discussed.

Another significant learning and reflection after reading Land Back: A Yellowhead Institute Red Paper was ongoing questions I reflected on of "how far?" (King \& Pasternak, 2019, p. 39). This verbiage is found on page 39 of Land Back: A Yellowhead Institute Red Paper within the following question: "But how far do these sharing agreements actually go in recognizing Indigenous jurisdiction and consent?" (King \& Pasternak, 2019, p. 39). While this quote was in relation to a specific agreement process ("Government Resource Revenue Sharing") (King \& Pasternak, 2019, p. 39), it sparked my reflection in relation to the degree of change which we engage with situated under ideas of 'reconciliation'. I also note that the authors of Land Back: A Yellowhead Institute Red Paper note that it "does not focus on policy and legislative changes that perpetuate this "politics of recognition" (mostly due to lack of space)" (King \& Pasternak, 2019, p. 36).

In my experience of learning about decolonizing social work, I have reflected on the limitations of actions which are framed as 'reconciling', which may not reflect transformation, or systems change. I am not attempting to say that some spaces of social work do not or have not 
engaged in meaningful actions towards 'reconciliation', rather I reflect on the ways we engage with these, and ways which I believe they should be pushed further, especially with considering the ways which this profession is implicated in colonialism. This is further discussed within the implications section of this MRP, which is found below.

Further, the report Land Back: A Yellowhead Institute Red Paper does not declare that there is not any degree of helpfulness found in actions/changes that may exist along the "spectrum of consent" (as discussed on page 36 and page 48), rather from my interpretation, the report considers these experiences, and questions how far these changes have gone (impact), and considering the degree of which this is meaningful for different individuals and/or communities (King \& Pasternak, 2019). King and Pasternak (2019) assert the following:

As Crown strategies change and adapt small spaces are made to permit incremental progress for Indigenous communities. And while these result in "recognized" rights and some power over land and resources, they do not breathe life back into fulsome Indigenous jurisdiction (p. 48).

I note that in my reading and reflection, the Land Back: A Yellowhead Institute Red Paper does not aim to answer these questions (such as 'how far?') in their entirety (King \& Pasternak, 2019, p. 44). I reflect on this as there may be a variety of different experiences from community-to-community, and to me representing the importance of not generalizing what is meaningful to and for others. Further, this is represented in the following quote in the conclusion of "Part Three: Recognition" (King \& Pasternak, 2019, p. 44):

But can capitalism, and this type of extraction, be "Indigenized" in a way that maintains consistency with Indigenous worldviews and 
values? This is an open question, and not one this report is meant to answer. Rather, the communities engaged in recognition-based resource development will hopefully have those discussions and decide amongst themselves. (King \& Pasternak, 2019, p. 44)

The need to push for meaningful and critically positioned 'reconciling' further within social work practice is discussed later in this paper.

When we consider the impacts on health, culture, spirit, etc. and the experiences of violence which are occurring - to what extent are changes needed, and to what extent will changes take place? While I do not intend to explore a career in the field of law or one which specifically focuses only on land tenure or jurisdiction, this learning has pushed me to question 'how far' I am willing to envision and take action for changes (toward 'reconciliation' - addressing the legacies of settler colonialism in meaningful ways), and further allowing me to question why those 'boundaries' may or may not exist.

I recognize and would like to name that this conversation and discussion of learning in relation to my reading of Land Back: A Yellowhead Institute (King \& Pasternak, 2019) does not comprehensively address topics within this report. Rather, I reflect on the ways which reading this material has encouraged me to have increased practical understanding of some of the happenings related to this topic, and think critically about this learning and my own position with relation to these topics.

\section{Implications: For me, and For Decolonizing Social Work:}

In this section I have considered what this project (learning and journey) means for me moving forward as someone in the field of social work. 
I cautiously write about the implications of this project as I see the need to engage with authentic decolonizing which may not take place within a paper or project written from one person's perspective. Further, the implications of this project for me will exist beyond writing or learning from reading. This project has discussed issues that are connected to people's health and wellbeing, and access to culture and responsibility, (as we consider the impacts of settler colonialism, and environmental violence). While this search did not aim or intend to unveil narratives (as all references existed prior to submitting this project), I do not wish to diminish the importance and urgency of this topic. I am passionate about responsibility and hopeful transformation with regard to solidarity with the ongoing happenings of land and water defense, however I do not wish to situate this project as one which has suggestions for others and the implications this project may have for them. The implications of this topic connects to Indigenous sovereignty and while I see value of other's writing related to this topic, I believe the implications must also be realized in actions and in transformation outside of academia (and thus this project).

Upon my reflection, I feel that perhaps the most significant implication is a greater consideration (at the very least) of some of what has and is happening on the land and water within conversations or intentions of critically addressing dispossession, jurisdiction, access and treatment of land and water. For me, this is certainly not enough - but is perhaps a starting point as a person occupying space on Turtle Island. I have a greater understanding of how this relates to my journey in trying to consider my role in this field which is connected to actions of colonialism (Baskin, 2016, p.11-13; Coates, 2013, p. 64; Hiller \& Carlson, 2018, p. 52). With attempting to avoid a generalization of experiences, I hope to carry the knowledges I have gained from this project to my work in the future. I also problematize the ways which I perceive the 
acknowledgement of 'carrying learning' to my work moving forward considering the degree to which this topic and issues impacts individuals and communities - it is a privilege to learn in this space. With my learning and knowledge, I must also challenge where I may be complicit and engage in ways to challenge this. Further, based on my learnings of the connectedness of systems - I believe it is pertinent to consider the ways which this responsibility extends to question complicity, and when appropriate pose critical analysis to the systems which are connected and involved within this topic.

An implication has been shifts in the ways I understand connection to the land and water - with consideration of the complicated ways which colonialism has impacted this. As a person working in this field which has a harmful past (and present) as it contributes to settler colonialism (Baskin, 2016, p.11-13; Coates, 2013, p. 64; Hiller \& Carlson, 2018, p. 52), I feel it is a responsibility to do 'more' than say that there is a greater appreciation for/with my relation with Creation - a privileged relation I add as someone whose access to nature and connection to land and water is not associated with any risk or danger.

I undoubtedly see the urgent need for significant changes in the ways 'settler social work' may not often recognize or engage with topics related to land dispossession, extraction/natural resource development, and implications to Indigenous wellbeing and health. With this, I turn back to my learning from reading Tuck and Yang (2012) and carry responsibility in not wanting to co-opt language and verbiage of 'reconciliation' and 'decolonizing' in ways that may seemingly be led with good intent, but are not helpful to decolonizing settler colonialism, or tangibly helpful to Indigenous folks. I reflect on the ways this may be "dangerous in how it domesticates decolonization" (Tuck \& Yang, 2012, p. 3). I think significant changes are needed beyond this paper to address the implications of environmental violence (within a settler colonial 
state) and social work. Indigenous folks are doing this work, and making demands and requests, and identifying why this is critically important. Implications for social work may be better listening and amplifying what Indigenous folks are and have already been saying. This connects back to the writing by Hiller and Carlson (2018, p. 59) which identifies the conversation which exists on the extent non-Indigenous social workers/students engage with such topics as the treatment of Indigenous knowledges is considered appropriate, while balancing the need for Indigenous knowledges and understandings in this field of work which is rooted in settler colonialism. I anticipate an important part for me moving forward is considering the ways which I may be complicit in relation to these issues: “...the profession as a whole remains slow to interrogate settler colonialism as an ongoing structure of dispossession in which social work itself is complicit" (Hiller \& Carlson, 2018, p. 52). This is further discussed by Coates (2013) in Decolonizing Social Work:

Decolonizing efforts include exposing the values, beliefs and destructive practices that have contributed not only to the exploitation of Indigenous Peoples and their traditional territories, but also to the benefits of elitist economic priorities and methods accruing to the Global North. (Coates, 2013, p. 70)

As discussed on page 25 of Land Back: A Yellowhead Institute Red Paper, land "redistribution" is incredibly important to meaningful change in the colonial structures and has been presented and recommended by many (King \& Pasternak, 2019, p. 25). Knowing this, I believe it is important to include considerations of land and water when advocating for changes to the ways we interact in our system - whether that be in my personal life or in advocacy 
efforts. I think this also reflects the importance of ways we listen and attempt to provide support by listening to what folks have already shared and said.

I believe it is also important to name some of the limitations of my research journey as I recognize ways which my learning may be continued or be more inclusive. A limitation of this paper is recognizing that I have not adequately explored the ways which settler colonial systems and structures impact Black and Indigenous people of colour in related and/or unique ways. I recognize this as an area which I hope to engage with further learning in the future. Further, a limitation of my project is that it does not represent the ways which there has been significant social awareness and discussion of environmental violence towards Indigenous folks in various media platforms. I recognize this paper has not focussed or given space specifically to learning from the writing of individuals who speak about their own experiences with/while defending land and water. I see this as valuable and needed in my continued learning.

Within this journey, I have engaged in significant learning which has felt meaningful to my development as I attempted to engage in research which was within my capacity and attempted to prioritize respect. Further, with relation to the intentional ways I have attempted to address different areas of myself/this process within the methodology. By engaging in areas of my learning (beyond the constraints of this project), I have reflected on the ways which learning can take shape in many spaces and forms. With this, I have spent time learning more about gardening and increasing my awareness of the natural environment around me. These activities have contributed to my relation with this project - but I am also cognizant of the ways this was influenced by my experiences with privilege. Within the context of this topic, and amongst the ongoing pandemic, I have had the opportunity to come to my home, with access to these activities and spaces in safe ways. 
This research project (MRP) is not situated with expectations of providing ideas about how practice may be shifted, or even suggesting ways which others will/can authentically engage in ways to challenge the violence that is taking place. Rather, I have engaged in learning with relation to my positioning and lived experiences and can better appreciate the role I may have with this moving forward.

\section{Conclusion and Continuing Learning:}

It is important to recognize that I believe the journey of learning about decolonizing social work does not start and stop with this project. As discussed in the 'methodology' section, it was important for me to hold intentionality with this journey, and how my activities outside of 'reading and writing' may contribute to my 'reading and writing'. This project has allowed me to learn of decolonizing ways which research may take place and space, and inspired me to reflect on ways this may look like in the future for myself and my journeys. Returning back to the Petal Flower Framework from Kandossiwin (Absolon, 2011, p.), I have reflected on the importance for my learning to consider my learning and this journey beyond only my learning from texts or an exclusively text-based methodology. While this understanding of intentionally engaging with a more wholistic approach was in reference to the methodological framework (Absolon, 2011), I have reflected on ways which this may support my future learning endeavours.

I reflect on concluding thoughts and would like to say - I don't hold naivety that the ways which this research has taken shape and space could have been altered and I anticipate my reflections on this will change over time. As identified earlier, in this project I have attempted to prioritize respect and accountability as I learn amongst my own journey. This journey of research is over in the formal sense. I name these limitations with recognition of my own capacity and also in recognizing the ways I have applied care to this project in the ways I have been able. 
Finally, while this paper has taken place through reading and reflection of writing based on my interpretations - I reflect on the ways which I believe parts of my own experience and relationship with the natural environment around me has been impacted. In allowing space for time spent outdoors while returning to my family home, and with time spent slowing down to engage with the natural world. I share these reflections while also holding critiques of noncritical ecological engagement (in relation to colonial realties and impacts experienced by many Indigenous folks) as identified earlier in this paper by Hiller \& Carlson (2018). In better understanding some of my relationship with Creation, and with a better understanding of some of the happenings and treatment of land and water amongst the state of Canada -I anticipate my learning is more certainly not ending here. My intentions to engage with this topic do not stop here, and I reflect on the significant learning I have completed within the journey of this project. I appreciate where I had started, and hope to continue this learning in hopes of meaningful engagement and change in my personal and professional life. 


\section{References}

Absolon, K. (2010). Indigenous wholistic theory: A knowledge set for practice. First Peoples Child \& Family Review, 5(2), 74-87. doi:10.7202/1068933ar

Absolon, K. E. (2011). Kaandossiwin: How we come to know. Halifax \& Winnipeg: Fernwood Publishing.

Absolon, K. (2009). Navigating the landscape of practice: Dbaagmowin of a helper. In M. Hart, Sinclair, R., \& Bruyere, G. (2009). Wicihitowin: Aboriginal social work in Canada (pp. 172-199). Black Point: Fernwood Publishing.

All Eyes on Wet'suwet'en: International Call for Solidarity! (n.d.). Retrieved from http://unistoten.camp/alleyesonwetsuweten/

Anderson, K. (2010, October). Aboriginal women, water and health: Reflections from eleven First Nations, Inuit, and Métis grandmothers. Prairie Women's Health Centre of Excellence \& Atlantic Centre of Excellence for Women's Health Retrieved November 3, 2019, from http://www.pwhce.ca/pdf/womenAndWater.pdf.

Androff, D., Fike, C., \& Rorke, J. (2017). Greening social work education: Teaching environmental rights and sustainability in community practice. Journal of Social Work Education, 53(3), 399-413. doi:10.1080/10437797.2016.1266976

Arvin, M., Tuck, E., \& Morrill, A. (2013). Decolonizing feminism: Challenging connections between settler colonialism and heteropatriarchy. Feminist Formations, 25(1), 8-34. Doi:10.1353/ff.2013.0006

Bartlett, C., Marshall, M., \& Marshall, A. (2012). Two-eyed seeing and other lessons learned within a co-learning journey of bringing together indigenous and mainstream knowledges and ways of knowing. Journal of Environmental Studies and Sciences, 2(4), 331-340. doi:10.1007/s13412-012-0086-8

Baskin, C. (2016). Strong helpers' teachings: The value of Indigenous knowledges in the helping professions (2nd ed.). Toronto: Canadian Scholars’ Press. 
Brant Castellano, M. (2016) Elder's Teachings in the Twenty-First Century: A Personal Reflection. In Long, D., \& Dickason, O. P., Visions of the heart: Issues involving Aboriginal Peoples in Canada. (pp. 80-97). Oxford University Press.

Carroll, C., Garroutte, E., Noonan, C., \& Buchwald, D. (2018). Using PhotoVoice to promote land conservation and indigenous well-being in Oklahoma. Ecohealth, 15(2), 450-461. doi:10.1007/s10393-018-1330-9

Coates, J. (2013) Ecospiritual approaches: A path to decolonizing social work in Gray, M., Coates, J., Yellow Bird, M., \& Hetherington, T. (2013). Decolonizing Social work. Ashgate.

Corntassel, J., \& Hardbarger, T. (2019). Educate to perpetuate: Land-based pedagogies and community resurgence. International Review of Education, 65(1), 87-116. doi:10.1007/s11159-018-9759-1

Crosby, A., \& Monaghan, J. (2018). Policing indigenous movements: Dissent and the security state. Winnipeg: Fernwood Publishing.

Dominelli, L. (2014). Promoting environmental justice through green social work practice: A key challenge for practitioners and educators. International Social Work, 57(4), 338-345. doi: $10.1177 / 0020872814524968$

Freeman, B. M. (2019). Promoting global health and well-being of indigenous youth through the connection of land and culture-based activism. Global Health Promotion, 26(3_suppl), 17-25. doi:10.1177/1757975919831253 
Golden, D. M., Audet, C., \& Smith, M. A. (2015). "Blue-ice": Framing climate change and reframing climate change adaptation from the indigenous peoples' perspective in the northern boreal forest of Ontario, Canada. Climate and Development, 7(5), 401-413. doi:10.1080/17565529.2014.966048

Hart, M. (2009) For Indigenous People, by Indigenous People, with Indigenous People: Towards Indigenist Research Paradigm. In Hart, M., Sinclair, R., \& Bruyere, G. (2009). Wícihitowin: Aboriginal social work in Canada (pp. 153-169). Fernwood Pub.

Hart, M. (2009) Anti-colonial Indigenous social work. In Hart, M., Sinclair, R., \& Bruyere, G. (Eds.), Wicihitowin: Aboriginal social work in Canada (pp. 25-41). Fernwood Pub.

Hill, S. M. (2017). The clay we are made of: Haudenosaunee land tenure on the Grand River. Winnipeg, CA: University of Manitoba Press.

Hiller, C., \& Carlson, E. (2018). These are Indigenous lands: Foregrounding settler colonialism and Indigenous sovereignty as primary contexts for Canadian environmental social work. Canadian Social Work Review, 35(1), 45-70. doi:10.7202/1051102ar

Hoover, E. (2013). Cultural and health implications of fish advisories in a Native American community. Ecological Processes, 2(1), 1-12. doi:10.1186/2192-1709-2-4

Ineese-Nash, N. (2019;2020;). Is resistance enough? reflections of identity, politics, and relations in the "in-between" spaces of indigeneity and settlerhood. AlterNative : An International Journal of Indigenous Peoples, 16(1), 10-17. doi:10.1177/1177180119878239

Jeffery, D. (2014). Environmentalism in social work: What shall we teach? Affilia, 29, 492-498. doi:10.1177/ 0886109914533697

Johansen, B. E. (2020). Environmental racism in the united states and canada: Seeking justice and sustainability Praeger, an imprint of ABC-CLIO, LLC. 
King, H., \& Pasternak, S. (2019). Land back: A Yellowhead Institute red paper. Toronto: Yellowhead Institute. Including link

Konsmo, E. M, \& Kahealani Pacheco, A.M (2016). Violence on the land, violence on our bodies: Building an Indigenous response to environmental violence. Women's Earth Alliance, Native Youth Sexual Health Network. Retrieved from http://landbodydefense.org/uploads/files/VLVBReportToolkit2016.pdf

Lowan-Trudeau, G. (2017). Protest as pedagogy: Exploring teaching and learning in indigenous environmental movements. The Journal of Environmental Education, 48(2), 96-108. doi:10.1080/00958964.2016.1171197

Lowan-Trudeau, G. (2019). From reticence to resistance: Understanding educators' engagement with indigenous environmental issues in Canada. Environmental Education Research, 25(1), 62-74. doi:10.1080/13504622.2017.1422114

McGregor, D. (2004). Coming full circle: Indigenous knowledge, environment, and our future: Document view. American Indian Quarterly, 28(3/4), 385.

McGregor, D. (2016) All our relations: Aboriginal perspectives on Environmental Issues in Canada. In Long, D., \& Dickason, O. P., Visions of the heart: Issues involving Aboriginal Peoples in Canada. (pp. 21-50). Oxford University Press.

Palmateer, P. (2016). Shining light on the dark places: Addressing police racism and sexualized violence against Indigenous women and girls in the national inquiry. Canadian Journal of Women and Law, 28(2), 253-284. 
Richmond, C. (2018) The relatedness of people, land and health: Stories from Anishinabe Elders. In Greenwood, M., De Leeuw, S., \& Lindsay, N. M. (2018). Determinants of Indigenous Peoples' Health: Beyond the social (Second ed.). (pp. 167-187). Canadian Scholars. Toronto.

Tri-Council Policy Statement 2 (2018) - Chapter 9: Research involving the First Nations, Inuit and Métis Peoples of Canada. (2019). Government of Canada. Retrieved from“: https://ethics.gc.ca/eng/tcps2-eptc2_2018_chapter9-chapitre9.html?wbdisable=true\#c

Tobias, J.K., \& Richmond, C. A. M (2014) "That land means everything to us as Anishinaabe...": Environmental dispossession and resilience on the North Shore of Lake Superior. Health and Place, 29, 26-33.

Tsosie, R. (2012). Indigenous peoples and epistemic injustice: Science, ethics, and human rights. Washington Law Review, 87(4), 1133.

Tuck E., \& Yang, K. W. (2012). Decolonization is not a metaphor. Decolonization: Indigeneity, Education \& Society, 1(1), 1-40.

Vickery, J., \& Hunter, L. M. (2016). Native Americans: Where in environmental justice research? Society \& Natural Resources, 29(1), 36-52.

doi:10.1080/08941920.2015.1045644

Waldron, I. (2018). Women on the Frontlines: Grassroots Movements against Environmental Violence in Indigenous and Black Communities in Canada. Kalfou (Santa Barbara, Calif.), 5(2). https://doi.org/10.15367/kf.v5i2.211 
Wildcat, M., McDonald, M., Irlbacher-Fox, S., \& Coulthard, G. (2014). Learning from the land: Indigenous land based pedagogy and decolonization. Decolonization: Indigeneity, Education \& Society, 3(3).

Wilson, S. (2008). Research is ceremony: Indigenous research methods. Halifax \& Winnipeg: Fernwood Publishing

Wodak, R., \& Meyer, M. (2001). Methods of critical disco 